\title{
Can a single trial of a thoracolumbar myofascial release technique reduce pain and disability in chronic low back pain?
}

\section{Randomized balanced cross-over study}

Luana Rocha Paulo ${ }^{1}$, Ana Cristina Rodrigues Lacerda², Fábio Luiz Mendonça Martins³, José Sebastião Cunha Fernandes ${ }^{4}$, Leonardo Sette Vieira ${ }^{5}$, Cristiano Queiroz Guimarães ${ }^{6}$, Sílvia de Simoni Guedes Ballesteros ${ }^{7}$, Marco Túlio Saldanha dos Anjos ${ }^{8}$, Patrícia Aparecida Tavares ${ }^{9}$, Sueli Ferreira da Fonseca ${ }^{10}$, Murilo Xavier Oliveira ${ }^{11}$, Mário Bernardo-Filho ${ }^{12}$, Danúbia da Cunha de Sá-Caputo ${ }^{13}$, Vanessa Amaral Mendonça ${ }^{14}$ and Redha Taiar ${ }^{15, *}$

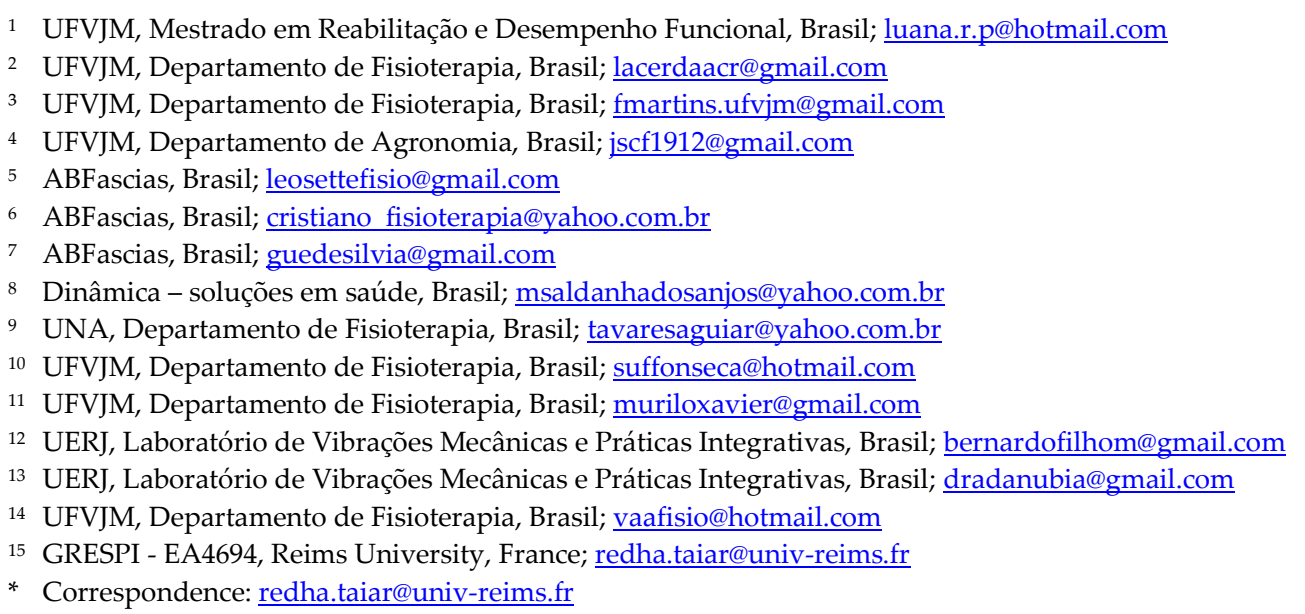

\begin{abstract}
Background: Although manual therapy for pain relief has been used as an adjunct in treatments for chronic low back pain (CLBP), there is still the belief that a single session of myofascial release would be effective. This study aimed to investigate whether a single session of a specific technique reduces pain and disability. (2) Methods: This was a crossover clinical trial in which 41 participants over 18 years old with CLBP were randomly enrolled into 3 situations - experimental, placebo, control, in a balanced and cross-over manner. The subjects underwent a single session of myofascial release on thoracolumbar fascia and compare it with the control and placebo. Outcome were pain and functionality, evaluated using the numerical pain rating scale (NPRS), pressure pain threshold (PPT) and Oswestry (ODI). (3) Results: There was no effects between-, within-tests, and interaction for all the outcomes, i.e., NPRS $\left(\eta^{2}=0.32, F=0.48, p=0.61\right)$, PPT $\left(\eta^{2}=\right.$ $0.73, F=2.80, p=0.06)$, ODI $\left(\eta^{2}=0.02, F=0.02, p=0.97\right)$. (4) Conclusion: A single trial of thoracolumbar myofascial release technique was not enough to reduce pain and disability in subjects with CLBP.
\end{abstract}

Keywords: fascia; chronic low back pain; myofascial release

\section{Introduction}

Chronic low back pain (CLBP) is an important undesirable health problem throughout the world [1]. Manual therapy (MT) is one of the possible management options to the treatment of CLBP ${ }^{[2-4]}$. Myofascial release is a form of MT, which involves the application of a low-load, and long-duration stretches to the myofascial complex and widely used by physical therapists in the management of CLBP ${ }^{[5-8]}$. 
Although previous reports point the effect of stabilization or global physical exercise in pain relief in subjects with CLBP compared to manual techniques isolated or adjunct [9-13], there is still the belief among clinicians that an isolated session of MT, e.g. myofascial release, is effective in reducing pain intensity and disability ${ }^{[2,14]}$.

As far as we know, only one study investigated the effects of an isolate myofascial release protocol on pain intensity and disability in patients with CLBP. Although the authors did not show clearly whether the improvement on pain intensity and disability was clinically relevant, they suggested the myofascial protocol used reduced these outcomes ${ }^{3}$. Therefore, the present study aims to verify if there is an immediate effect of a specific myofascial release protocol on TLF of individuals with nonspecific CLBP, concerning pain intensity and disability, in comparison with control and placebo situations $[15,16]$.

\section{Materials and Methods}

\subsection{Study Design}

This was a crossover open clinical trial performed between February and June 2019. The trial was registered with the Clinical Trials Government Identifier (ReBEC - reference number 8197). The current study conforms to the Consolidated Standards of Reporting Trials statement for reporting clinical trial studies. All subjects provided written informed consent to participate in this study, which was conducted in accordance with ethical principles for research involving humans (principles of the Declaration of Helsinki) and received approval from the Ethics and Research Committee of the Universidade Federal dos Vales do Jequitinhonha e Mucuri (reference number 3.435.537).

All the participants underwent three situations in a randomized and balanced order. The sequence of situations was randomized using a website (www.random.org). Firstly, a familiarization with the experimental procedures was performed, followed by anamnesis (age, sex, and level of physical activity) and evaluation of the prognosis or risk profile using STarT Back Screening Tool (SBST) questionnaire, which consists of 9 items divided into physical and psychosocial subscales ${ }^{[17]}$.

\subsection{Study Populations}

Subjects were recruited in the city of Diamantina, Minas Gerais, Brazil. Inclusion requirements and eligibility were: men and women over 18 years old, with a medical diagnosis of CLBP or low back pain for more than 3 months, who had at least 2-3 points of pain by the Numerical Pain Rating Scale (NPRS) during data collection and with low or sedentary level of physical activity ${ }^{[18,19]}$. Exclusion criteria were: historic of previous or scheduled surgeries in the torso or limbs, as well as those with suspicion of severe fractures or pathologies (tumor, inflammation or infection, rheumatological disorder, aortic aneurysm); diagnosis of radiculopathy or neuropathy (with or without spinal canal stenosis with proof of magnetic resonance imaging - MRI); structural deformity in the spinal column; spondyloarthropathy, syndrome of the equine tail, significant movement limitation, disabling pain and physical disability that would make it impossible to perform the study procedures; use of painkillers or anti-inflammatory medicines 48 hours before the first test phase or during the study; neurological or psychiatric disorder; presence or suspicion of pregnancy.

\subsection{Sample Size Calculation}

The sample size was estimated by the GPower ${ }^{\circledR}$ program (Franz Faul, Universitat Kiel, Germany), version 3.1.9.2. For this, we used analysis A priori, considering ANOVA for comparisons between groups, for the variable NPRS [20]. The effect size was calculated from the difference in the means with standard deviation within each group of 0.9 . Thus, considering an effect size of 0.42 , power of $0.80 \%$, and alpha error $5 \%$, the sample size 
was estimated at 41 volunteers. There was no withdrawal, so there was no need to analyze the data with the intention to treat.

A total of 52 subjects accepted to participate, from them, 10 individuals gave up or did not attend the test site on the scheduled date and 1 individual did not meet the described inclusion criteria. Therefore, 41 subjects participated in all stages of the research (Figure 1). Of the total of 41 individuals, 61\% were women and 56\% declared themselves sedentary. In addition, the mean age was 36 years and the self-reported pain averaged 3.4 to 3.7 points. Among the subjects, $56 \%$ were classified in terms of poor prognosis in the SBST as low risk (Table 1).

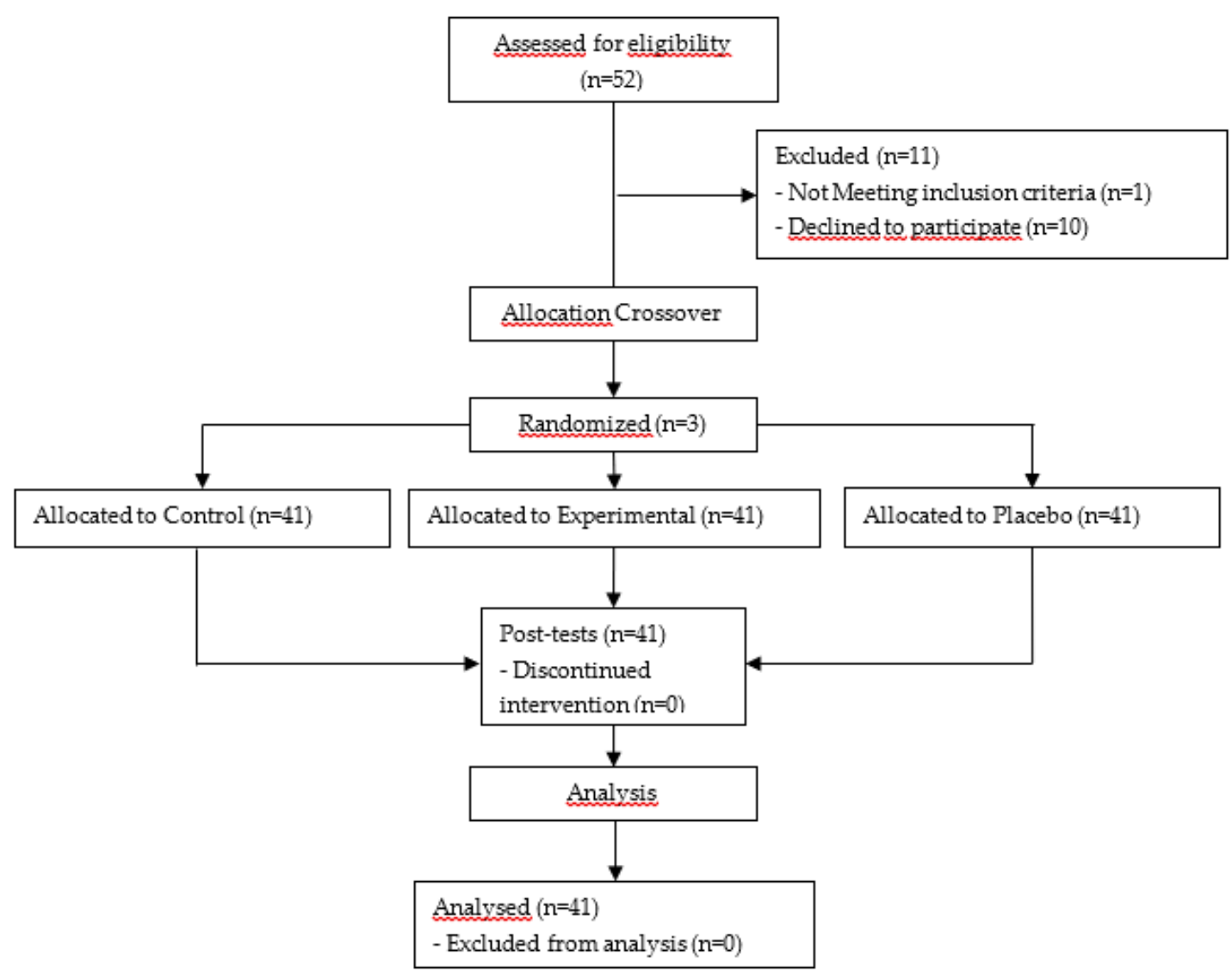

Figure 1. Design and flow of participants through the trial. 
Table 1. Characteristics of the participants and baseline.

\begin{tabular}{|c|c|}
\hline Characteristics & $\begin{array}{c}\text { Subjects }(n=41) \\
\text { Mean }\left(95 \% C I^{*}\right) \text { or } \%\end{array}$ \\
\hline Age (years) & $36(22-50)$ \\
\hline Gender, women (\%) & 60.98 \\
\hline Sedentary (\%) & 56.09 \\
\hline NRPS 1 baseline $(0-10)$ & 3.68 (1.39-5.97) \\
\hline $\mathrm{PPT}^{2}\left(\mathrm{~N} / \mathrm{cm}^{2}\right)$ & $34(16.57-51.43)$ \\
\hline \multicolumn{2}{|l|}{$\mathrm{SBST}^{3}$ - prognosis (\%) } \\
\hline - Lowrisk & 56.1 \\
\hline - Medium risk & 24.4 \\
\hline - High risk & 19.5 \\
\hline
\end{tabular}

\subsection{Outcome measures}

The measurements of the pain were the primary outcome. Pressure Pain Threshold (PPT) and NPRS were used as instruments. As a secondary outcome, Oswestry Disability Index questionnaire (ODI - version 2.0) was applied to evaluate the prognosis and functionality of the subjects. All analyses were performed to compare the results before and immediately after each experimental situation.

For pain measurements, the NPRS was used to quantify the intensity of pain in all arms of the study, ranging from 0 to 10, with 0 classified as no pain and 10 the worst pain imaginable. This instrument has proved to be a concurrent and valid predictor as a measure of pain intensity [21]. The pain threshold was assessed using a PPT device (Wagner Instruments, FDX series, USA), with a graduation capacity of 50x0.05 lbf, $800 \times 0.5 \mathrm{ozf}, 25 \times 0.02 \mathrm{kgf}$ and $250 \times 0.2 \mathrm{~N}, 1 \mathrm{~cm}^{2}$ plunger connected to a mechanical force gauge that indicates the pressure applied at the marked location. The measurements with this instrument were made before each situation and immediately after. The plunger of the device was positioned perpendicular to the paravertebral muscle, respecting the proximity of $2 \mathrm{~cm}$ lateral to the midline between the L3-L4 spinous process. The pressure was applied progressively, with an average of $100 \mathrm{~g} \cdot \mathrm{sec}^{-1}$, until the volunteer signaled the onset of pain or discomfort. After signaling, the device was removed from contact with the individual's body and Newton's quantification was noted [22,23].

The ODI Version 2.0 questionnaire ${ }^{[24]}$ was used to quantify the disability caused by low back pain in daily activities. Scores were given from $0 \%$ (no dysfunction; independence) to $100 \%$ (lowest level of functionality; total dependence), divided into 5 levels where the first described no limitation and the others described limitation or inability to function. The total score is the percentage value calculated by the following equation: Total score $=(\Sigma$ item score $/ 50) \times 100$. With all 10 questions answered, the total score was divided by 50 (10 x 5). Published minimally clinically important difference (MCID) values for ODI is 12.88 (sensitivity $88 \%$, specificity $85 \%$ ) [25]. It must be taken into consideration that the ODI is a questionnaire with a one-dimensional factorial structure, important psychometric properties, and internal consistency, and its ability to measure functional limitations was considered very accurate, according to the actual severity level of the experienced dysfunction, by the evaluated subjects ${ }^{[26]}$.

\subsection{Intervention}

Forty-one of the fifty-two volunteers were selected after the initial screening and exclusion through the eligibility criteria. All were enrolled in the three situations: 1) control (C), 2) experimental (Exp), and 3) placebo (Plac), and performed on consecutive days respecting a minimum interval of 24 hours in order to minimize the potential bias due to the high level of adaptability of the connective tissue ${ }^{[2]}$. 
C. The subjects were instructed to remain in the supine position for five minutes on a stretcher to minimize the effects of tension forces or stimuli on the tissue, without making movements, in order to mimic the time spent in the act of performing the intervention.

Exp. The subjects underwent a single session of the new approach to be tested to release the TLF, in sedestation position with feet supported and the thoracolumbar region properly undressed. A single trained therapist positioned the hands without sliding over the skin or forcing the tissue, with the cranial hand close to the last rib and at the T12-L1 level on the right side of the individual's body and the caudal hand on the ipsilateral side between the iliac crest and the sacrum, causing a slight traction in the tissues, moving the hands away in a longitudinal direction. Then, the participant was instructed to perform five repetitions of active trunk flexion-extension $\left(30^{\circ}\right)$ and extension, while the researcher followed the movement with both hands simultaneously positioned, without losing the initial tissue traction and position. The same technique and the same number of repetitions of active trunk flexion-extension were repeated with the researcher's hands positioned on the other side. This technique lasts approximately five minutes $[2,27,28]$.

Plac. The subjects were not submitted to the technique of manual thoracolumbar fascia release, but they slowly performed ten repetitions of active trunk flexion-extension $\left(30^{\circ}\right)$ in the same position as the experimental situation.

\subsection{Statistical Analysis}

Data was described as Mean (95\% Confidence Interval). The normality and homogeneity of the variables were assessed by the Shapiro-Wilk test and the Levene test, respectively. The effects and interactions in the two moments (pre and post) and three situations (C, Plac, Exp) were evaluated by factorial variance analysis (ANOVA $2 \times 3$ ) allowing comparisons between-tests, within-tests, and interaction. Tukey test was used as a Post Hoc for multiple comparisons of means. The level of significance adopted for all tests was $5 \%$. Estimates of effect size and power were calculated using the GPower ${ }^{\circledR}$ program version 3.1.

\section{Results}

There was no statistical difference between-, within-tests, and interaction. The minimal detectable change ((MDC95: post - pre) for PPT was 3\% (- 1.14 points) to the control, $8 \%$ (+2.45 points) to the placebo, and $13 \%$ (+ 4.28 points) to the experimental. The MDC95 for NPRS was $0.005 \%$ to the control, $0.09 \%$ to the placebo, and $0.04 \%$ to the experimental, i.e., a change less than 0.3 points in the NPRS. The MDC95 for ODI was $13 \%$ ( +2.22 points) to the control, $2 \%$ (+ 0.19 points) to the placebo, and $1 \%$ ( 0.03 points) to the experimental (Table 2). 
Table 2. This is a table. Tables should be placed in the main text near to the first time they are cited.

CI: confidence interval; NPRS: visual numeric pain scale; PPT: pressure pain threshold (N: Newtons); ODI: Oswestry Disability Index. $\eta^{2}$ : Eta partial. N $=41$. Factorial ANOVA 2 (2x3).

\begin{tabular}{|c|c|c|c|c|c|c|c|c|c|c|c|c|c|c|c|}
\hline \multirow[t]{2}{*}{ Outcomes } & \multirow[t]{2}{*}{$\begin{array}{c}\text { Control } \\
\text { Mean }(95 \% \mathrm{CI})\end{array}$} & \multirow[t]{2}{*}{$\begin{array}{c}\text { Placebo } \\
\text { Mean (95\% CI) }\end{array}$} & \multirow[t]{2}{*}{$\begin{array}{c}\text { Experimental } \\
\text { Mean }(95 \% \mathrm{CI})\end{array}$} & \multicolumn{4}{|c|}{ Between-tests } & \multicolumn{4}{|c|}{ Within-tests } & \multicolumn{4}{|c|}{ Interaction } \\
\hline & & & & $p$ & $\mathrm{~F}$ & $\eta^{2}$ & Power & $P$ & $\mathrm{~F}$ & $\eta^{2}$ & Power & $p$ & $\mathrm{~F}$ & $\eta^{2}$ & Power \\
\hline $\mathrm{PPT}\left(\mathrm{N} / \mathrm{cm}^{2}\right)$ pre & $37.25(32.63-41.86)$ & $29.37(23.93-34.81)$ & $30.38(24.70-36.06)$ & \multirow[b]{2}{*}{0.40} & \multirow[b]{2}{*}{0.90} & \multirow[b]{2}{*}{0.47} & \multirow[b]{2}{*}{0.99} & \multirow[b]{2}{*}{0.56} & \multirow[b]{2}{*}{0.34} & \multirow[b]{2}{*}{0.25} & \multirow[b]{2}{*}{0.90} & \multirow[b]{2}{*}{0.06} & \multirow[b]{2}{*}{2.80} & \multirow[b]{2}{*}{0.73} & \multirow[b]{2}{*}{1.00} \\
\hline $\mathrm{PPT}\left(\mathrm{N} / \mathrm{cm}^{2}\right)$ post & $36.11(30.90-41.31)$ & $31.82(26.12-37.52)$ & $34.66(28.01-41.32)$ & & & & & & & & & & & & \\
\hline NPRS (score) pre & $3.41(2.69-4.12)$ & $3.80(3.06-4.53)$ & $3.00(2.30-3.69)$ & \multirow[b]{2}{*}{0.06} & \multirow[b]{2}{*}{2.79} & \multirow[b]{2}{*}{0.73} & \multirow[b]{2}{*}{1.00} & \multirow[b]{2}{*}{0.80} & \multirow[b]{2}{*}{0.06} & \multirow[b]{2}{*}{0.05} & \multirow[b]{2}{*}{0.25} & \multirow[b]{2}{*}{0.61} & \multirow[b]{2}{*}{0.48} & \multirow[b]{2}{*}{0.32} & \multirow[b]{2}{*}{0.97} \\
\hline NPRS (score) post & $3.43(2.76-4.09)$ & $3.48(2.73-4.22)$ & $3.14(2.38-3.89)$ & & & & & & & & & & & & \\
\hline ODI (\%) pre & $15.82(12.91-18.74)$ & 17.51(14.42-20.59) & $19.26(16.29-22.23)$ & \multirow[b]{2}{*}{0.007} & \multirow[b]{2}{*}{5.01} & \multirow[b]{2}{*}{0.83} & \multirow[b]{2}{*}{1.00} & \multirow[b]{2}{*}{0.73} & \multirow[b]{2}{*}{0.11} & & & & & & \\
\hline ODI (\%) post & $18.04(15.00-21.09)$ & $17.70(14.65-20.76)$ & $19.29(16.22-22.36)$ & & & & & & & 0.07 & 0.31 & 0.97 & 0.02 & 0.02 & 0.11 \\
\hline
\end{tabular}




\section{Discussion}

The aim of the study was to verify if there is an immediate effect of a single specific protocol of myofascial release on TLF with trunk flexion-extension of individuals with nonspecific CLBP, concerning pain intensity and disability, in comparison with control and placebo situations. As it was suggested, the main findings demystified the belief that an isolated trial of manual therapy, as well as the thoracolumbar myofascial release technique, reduces pain and improves functionality in subjects with CLBP. Although six participants showed a reduction in the NPRS consistent with the MCID [21,29,30], the magnitude of the subjects' pain measured by NPRS was not statistically significant between-, within-tests, and interaction.

These results probably have suffered interference related to the heterogeneity of the studied population regarding the poor prognosis by SBST, with $56 \%$ of the participants classified as low-risk, $24.4 \%$ medium risk and 19.5\% high-risk. In addition, four participants of high-risk and two from the medium risk obtained a significant improvement at NPRS in the intervention situation. According to Fritz et al (2011), there is a relationship between the risk categories and the magnitude of the participants' improvement at the end of the analysis, in which individuals with a higher risk of poor prognosis, presented a greater report of pain attenuation ${ }^{[17]}$.

Regarding PPT measure, no significant difference was observed between-, within-tests, and interaction. In addition, the average value found in the present study was around $34 \mathrm{~N} / \mathrm{cm}^{2}\left(3.5 \mathrm{Kgf} / \mathrm{cm}^{2}\right)$ representing a threshold lower than that reported in the literature ${ }^{[23,31]}$. According to Fischer (1987), asymptomatic people are expected to report pain or discomfort to PPT test when reaching $55 \mathrm{~N} / \mathrm{cm}^{2}\left(5.6 \mathrm{kgf} / \mathrm{cm}^{2}\right)$ in men and $37 \mathrm{~N} / \mathrm{cm}^{2}$ $\left(3.8 \mathrm{kgf} / \mathrm{cm}^{2}\right)$ in women, while Pöntinen (1998) found a pain threshold of $39 \mathrm{~N} / \mathrm{cm}^{2}(4.0$ $\mathrm{kgf} / \mathrm{cm}^{2}$ ) in a research with participants with CLBP.

Concerning functionality, the ODI questionnaire revealed no significant difference between-, within-tests, and interaction. Lauridsen et al (2006) evaluated the response capacity of the ODI and MCID of ODI for patients with CLBP and pointed out that a MCID around 12 - 13 points are clinically important. In addition, in the present study, the interval between applications of the questionnaires was 24 hours, which probably influenced the results obtained, as it reduced confounding and memory factors, beyond isolating the natural course over time, since the objective was to evaluate the technique effectiveness acutely. The article on the development of the Brazilian version of the ODI [24] discusses this interference of the retest time in the results, also informs that a longer interval improves the chances of reducing the final percentage due to the influence of the natural course of the associated CLBP symptoms.

The time factor calls into question the need to follow-up, because in addition to the natural course of low back pain, it is known that a short-term MT intervention can improve pain and disability, but without retention effects after three-months follow-up [4]. Nevertheless, habitual loading will result in a high rate of collagen synthesis in a basal state simply as result of a constant effect of loading from the previous 24-48h. Magnusson et al (2010) observed that after cessation of exercise and up to 18-36h thereafter, there is a negative net balance in collagen levels, whereas the balance is positive for up to $72 \mathrm{~h}$ after exercise. However, the connective tissue requires a certain restitution period, since, without sufficient rest, a continuous loss of collagen is likely to occur, which might render the tissue vulnerable. Habitual physical exercises thus results in a higher turnover of collagen, whereas inactivity lowers collagen synthesis and turnover ${ }^{[32]}$.

According to the literature, physical exercises are the most used resources in conservative treatment and in the prevention of chronic pain, being performed in different modalities, duration and intensity according to the complaint, health status and final objective, in addition to being associated with multimodal or multidisciplinary treatments $[10-12,33,34]$. In this work, the performance of physical exercises, according to the level 
of physical activity self-reported by the sample, may also have interfered in the outcomes. $44 \%$ of the sample considered themselves active, but doing vigorous exercise less than 3 times per week, or moderate physical activity less than 5 times per week, this information do not meet the guidelines of the American College of Sports Medicine for health benefits ${ }^{[19]}$. Even though the level of physical activity is not significant, this information may have influenced the results.

Furthermore, the fascial system showed that it has a high level of adaptability responding to changes in internal and external conditions, in addition to responding to changes of remote areas of the intervention, as well as pain could be the result of a tissue alteration distant from the reported region according to the tensegrity model [35-37]. The fascial system is also able to alter its shape and manage modifications in movement and different regulations of body functions [15,38,39]. Studies indicate that TLF is densely innervated by mechanoreceptors which are responsive to MT [5], repeated mechanical or biochemical stimulation. $45 \%$ of these neurons have a low mechanical threshold and can be activated by weak stimuli such as a non-harmful local pressure and most of these tend to actively reduce their threshold for nociception causing persistent pain [7,840].

Studies have shown that different mechanical stimulus in the lumbar region (TLF) can improve movement, facilitate muscle control, reduce tissue inflammatory factors and produce immediate neurophysiological changes in sympathetic nervous system function and the endogenous pain inhibitory systems, that triggers an activation of the insular cortex causing a sense of well-being and social belonging [7,15,16,35,41-50]. Notwithstanding, myofascial release, even as other MT techniques, is always accompanied by several benefits reaffirmed by those who use and receive it. This reinforces the patient's belief and perception of the intervention, and a complex set of physical and psychological stimuli that can influence their outcome, as well as the interaction between the therapist and the patient and the expectation of both in the treatment ${ }^{[35,44,51,52]}$.

Considering these facts, it is consensus that non-specific CLBP has biological, psychological, and social components in several different extensions, beyond of biomechanics in its development. It must be considered that each subject has different painful experiences and different outcomes throughout life, where multiple areas of the brain are activated during a pain experience ${ }^{[35,53]}$. Moreover, these central areas have other primary functions, i.e., movement execution, sensory location, and emotional awareness which are overloaded in chronic pain, and may explain the emergence of psychosocial problems among other motor and sensory changes that are beyond the scope of this study [44,53,54].

The multi-causality and variety of outcomes presented by chronic pain, in addition to the non-linear interaction arising from the complexity of the interaction of causal factors, may explain the fact that a single session of myofascial mobilization was not enough to modify the threshold and intensity of the pain and functional capacity [43,55,56]. Additionally, a rehabilitation program focused not only on tissue but also on complementary issues such as exercise, pain education and behavioral strategies is important $[43,44,52,57,58]$.

\subsection{Limitations}

Most of the sample had a low risk of poor prognosis to SBST, which proved to be an important limitation for obtaining results on pain and disability outcomes. In addition, the interval between experimental situations was very short in relation to the time of tissue adaptation, in addition to the ODI showing better results in reapplication when there is interference in the natural course of CLBP.

According to the baseline, part of the sample performed some type of physical exercise, which is a factor that may have contributed to the SBST classification and to the final results, since the exercises have positive effects against chronic pain.

No consecutive sessions were analyzed, as the aim of the research was to verify immediate results of fascial mobilization and the time of the technique may have been 
short to obtain a positive result, therefore a time-dependent analysis with follow up would be more appropriate.

Another limitation is that there is still no way to quantify the pressure applied by the therapist's hand during manual therapy techniques, making it difficult to reproduce the studied technique.

\section{Conclusions}

This study provides evidence that a single trial of thoracolumbar myofascial release technique was not enough to reduce pain and disability in subjects with CLBP. Further investigations associating other interventions with myofascial mobilization are required, as well as prolonged treatments. The mechanisms underlying these responses merit further investigation. As a perspective, we suggest the design of studies with an approach to the biopsychosocial aspects presented by individuals with CLBP, besides analysing the effects of myofascial mobilization at the structural level of the tissue.

Author Contributions: Conceptualization, L.R.P., L.S.V., A.C.R.L. and F.L.M.M.; methodology, A.C.R.L. and L.R.P..; validation, L.R.P., L.S.V., A.C.R.L., C.Q.G. and F.L.M.M.; formal analysis, J.S.C.R.; investigation, L.R.P.; resources, L.R.P., S.S.G.B. and P.A.T.; data curation, L.R.P., A.C.R.L. and J.S.C.R.; writing-original draft preparation, L.R.P.; writing-review and editing, L.R.P., A.C.R.L. M.T.S.A., M.X.O., S.F.F., R.T., M.B.F. and V.A.M.; visualization, L.R.P, A.C.R.L, R.T. and F.L.M.M.; supervision, F.L.M.M. and A.C.R.L.; project administration, L.R.P.; funding acquisition, L.R.P. All authors have read and agreed to the published version of the manuscript.

Funding: This research received no external funding.

Institutional Review Board Statement: The study was conducted according to the guidelines of the Declaration of Helsinki, and approved by the Institutional Ethics and Research Committee of Universidade Federal dos Vales do Jequitinhonha e Mucuri (protocol code 3.435.537 in July 03, 2019).

Informed Consent Statement: Informed consent was obtained from all subjects involved in the study.

Acknowledgments: Volunteers, authors and collaborators. Equipment loan and providing the technique used in the experiment: Leonardo Sette, Cristiano Queiroz, Sílvia Ballesteros and Patrícia Tavares. Place for data collections: UFVJM.

Conflicts of Interest: The authors declare no conflict of interest.

\section{References}

(1) Vos, T.; Barber, R. M.; Bell, B.; Bertozzi-Villa, A.; Murray, C. J. L.; et al. Global, Regional, and National Incidence, Prevalence, and Years Lived with Disability for 301 Acute and Chronic Diseases and Injuries in 188 Countries, 1990-2013: A Systematic Analysis for the Global Burden of Disease Study 2013. Lancet 2015, 386 (9995), 743-800.

Ajimsha, M. S.; Daniel, B.; Chithra, S. Effectiveness of Myofascial Release in the Management of Chronic Low Back Pain in Nursing Professionals. J. Bodyw. Mov. Ther. 2014, 18 (2), 273-281.

Arguisuelas, M. D.; Lisón, J. F.; Sánchez-Zuriaga, D.; Martínez-Hurtado, I.; Doménech-Fernández, J. Effects of Myofascial Release in Non-Specific Chronic Low Back Pain: A Randomized Clinical Trial. Spine (Phila. Pa. 1976). 2017, 42 (9), 627-634.

Boff, T. A.; Pasinato, F.; Ben, Â. J.; Bosmans, J. E.; van Tulder, M.; Carregaro, R. L. Effectiveness of Spinal Manipulation and Myofascial Release Compared with Spinal Manipulation Alone on Health-Related Outcomes in Individuals with Non-Specific Low Back Pain: Randomized Controlled Trial. Physiother. (United Kingdom) 2020, 107, 71-80.

(5) Arguisuelas, M. D.; Lisón, J. F.; Coloma, P. S. Clinical Biomechanics Effects of Myofascial Release in Erector Spinae Myoelectric Activity and Lumbar Spine Kinematics in Non-Specific Chronic Low Back Pain : Randomized. Clin. Biomech. 2019, 63 (February), 27-33. 
(8) Schilder, A.; Hoheisel, U.; Magerl, W.; Benrath, J.; Klein, T.; Treede, R. D. Sensory Findings after Stimulation of the Thoracolumbar Fascia with Hypertonic Saline Suggest Its Contribution to Low Back Pain. Pain 2014, 155 (2), $222-231$.

(9) Akhtar, M. W.; Karimi, H.; Gilani, S. A. Effectiveness of Core Stabilization Exercises and Routine Exercise Therapy in Management of Pain in Chronic Nonspecific Low Back Pain: A Randomized Controlled Clinical Trial. Pakistan J. Med. Sci. 2017, 33 (4), 1002-1006.

(10) Searle, A.; Spink, M.; Ho, A.; Chuter, V. Exercise Interventions for the Treatment of Chronic Low Back Pain: A Systematic Review and Meta-Analysis of Randomised Controlled Trials. Clin. Rehabil. 2015, 29 (12), 1155-1167.

(11) van Middelkoop, M.; Rubinstein, S. M.; Verhagen, A. P.; Ostelo, R. W.; Koes, B. W.; van Tulder, M. W. Exercise Therapy for Chronic Nonspecific Low-Back Pain. Best Pract. Res. Clin. Rheumatol. 2010, 24 (2), 193-204.

(12) Van Middelkoop, M.; Rubinstein, S. M.; Kuijpers, T.; Verhagen, A. P.; Ostelo, R.; Koes, B. W.; Van Tulder, M. W. A Systematic Review on the Effectiveness of Physical and Rehabilitation Interventions for Chronic Non-Specific Low Back Pain. Eur. Spine J. 2011, 20 (1), 19-39.

Wang, X. Q.; Zheng, J. J.; Yu, Z. W.; Bi, X.; Lou, S. J.; Liu, J.; Cai, B.; Hua, Y. H.; Wu, M.; Wei, M. L.; Shen, H. M.; Chen, Y.; Pan, Y. J.; Xu, G. H.; Chen, P. J.; Eldabe, S. A Meta-Analysis of Core Stability Exercise versus General Exercise for Chronic Low Back Pain. PLoS One 2012, 7 (12), 1-7.

(14) Ozsoy, G.; Ilcin, N.; Ozsoy, I.; Gurpinar, B.; Buyukturan, O.; Buyukturan, B.; Kararti, C.; Sas, S. Response to: Non-Specific Low Back Pain in Elderly and the Effects of Myofascial Release Technique Combined with Core Stabilization Exercise: Not Just Muscles [Response to Letter]. Clin. Interv. Aging 2019, 14, 1947-1949..

(15) Bordoni, B.; Marelli, F.; Morabito, B.; Sacconi, B. The Indeterminable Resilience of the Fascial System. J. Integr. Med. 2017, 15 (5), 337-343.

(16) Findley, T.; Chaudhry, H.; Stecco, A.; Roman, M. Fascia Research - A Narrative Review. J. Bodyw. Mov. Ther. 2012, 16 (1), $67-75$.

(17) Fritz, J. M.; Beneciuk, J. M.; George, S. Z. Relationship between Categorization with the STarT Back Screening Tool and Prognosis for People Receiving Physical Therapy for Low Back Pain. Phys. Ther. 2011, 91 (5), 722-732.

(18) Lauridsen, H. H.; Hartvigsen, J.; Manniche, C.; Korsholm, L.; Grunnet-Nilsson, N. Responsiveness and Minimal Clinically Important Difference for Pain and Disability Instruments in Low Back Pain Patients. BMC Musculoskelet. Disord. 2006, 7, $1-16$.

(19) Martin, S. B.; Morrow, J.; Jackson, A. W.; Dunn, A. L. Variables Related to Meeting the CDC/ACSM Physical Activity Guidelines. Med. Sci. Sports Exerc. 2000, 32 (12), 2087-2092.

(20) Bhadauria, E. A.; Gurudut, P. Comparative Effectiveness of Lumbar Stabilization, Dynamic Strengthening, and Pilates on Chronic Low Back Pain: Randomized Clinical Trial. J. Exerc. Rehabil. 2017, 13 (4), 477-485.

(21) Childs, J. D.; Piva, S. R.; Fritz, J. M. Responsiveness of the Numeric Pain Rating Scale in Patients with Low Back Pain. Spine (Phila. Pa. 1976). 2005, 30 (11), 1331-1334.

(22) Antonaci, F.; Sand, T.; Lucas, G. A. Pressure Algometry in Healthy Subjects: Inter-Examiner Variability. Scand. J. Rehabil. Med. 1998, 30 (1), 3-8.

(23) Pöntinen, P. J. Reliability, Validity, Reproducibility of Algometry in Diagnosis of Active and Latent Tender Spots and Trigger Points. J. Musculoskelet. Pain 1998, 6 (1), 61-71.

(24) Vigatto, R.; Alexandre, N. M. C.; Filho, H. R. C. Development of a Brazilian Portuguese Version of the Oswestry Disability Index. Spine (Phila. Pa. 1976). 2007, 32 (4), 481-486.

(25) Johnsen, L. G.; Hellum, C.; Nygaard, Ø. P.; Storheim, K.; Brox, J. I.; Rossvoll, I.; Leivseth, G.; Grotle, M. Comparison of the SF6D, the EQ5D, and the Oswestry Disability Index in Patients with Chronic Low Back Pain and Degenerative Disc Disease. BMC Musculoskelet. Disord. 2013, 14.

(26) Saltychev, M.; Mattie, R.; McCormick, Z.; Bärlund, E.; Laimi, K. Psychometric Properties of the Oswestry Disability Index. 
Int. J. Rehabil. Res. 2017, 40 (3), 202-208.

(27) Chaitow, L. What's in a Name: Myofascial Release or Myofascial Induction? J. Bodyw. Mov. Ther. 2017,21 (4), 749-751.

(28) Martínez-Jiménez, E. M.; Becerro-de-Bengoa-Vallejo, R.; Losa-Iglesias, M. E.; Rodríguez-Sanz, D.; Díaz-Velázquez, J. I.; Casado-Hernández, I.; Mazoteras-Pardo, V.; López-López, D. Acute Effects of Myofascial Induction Technique in Plantar Fascia Complex in Patients with Myofascial Pain Syndrome on Postural Sway and Plantar Pressures: A Quasi-Experimental Study. Phys. Ther. Sport 2020, 43, 70-76.

(29) Farrar, J. T.; Young, J. P.; LaMoreaux, L.; Werth, J. L.; Poole, R. M. Clinical Importance of Changes in Chronic Pain Intensity Measured on an 11-Point Numerical Pain Rating Scale. Pain 2001, 94 (2), 149-158.

(30) Kovacs, F. M.; Abraira, V.; Royuela, A.; Corcoll, J.; Alegre, L.; Cano, A.; Muriel, A.; Zamora, J.; Gil Del Real, M. T.; Gestoso, M.; Mufraggi, N. Minimal Clinically Important Change for Pain Intensity and Disability in Patients with Nonspecific Low Back Pain. Spine (Phila. Pa. 1976). 2007, 32 (25), 2915-2920.

(31) Fischer, A. A. Pressure Algometry over Normal Muscles. Standard Values, Validity and Reproducibility of Pressure Threshold. Pain 1987, 30 (1), 115-126.

(32) Magnusson, S. P.; Langberg, H.; Kjaer, M. The Pathogenesis of Tendinopathy: Balancing the Response to Loading. Nat. Rev. Rheumatol. 2010, 6 (5), 262-268.

(33) Gomes-Neto, M.; Lopes, J. M.; Conceição, C. S.; Araujo, A.; Brasileiro, A.; Sousa, C.; Carvalho, V. O.; Arcanjo, F. L. Stabilization Exercise Compared to General Exercises or Manual Therapy for the Management of Low Back Pain: A Systematic Review and Meta-Analysis. Phys. Ther. Sport 2017, 23, 136-142.

(34) Coulombe, B. J.; Games, K. E.; Neil, E. R.; Eberman, L. E. Core Stability Exercise versus General Exercise for Chronic Low Back Pain. J. Athl. Train. 2017, 52 (1), 71-72.

(35) Bishop, M. D.; Torres-Cueco, R.; Gay, C. W.; Lluch-Girbés, E.; Beneciuk, J. M.; Bialosky, J. E. What Effect Can Manual Therapy Have on a Patient's Pain Experience? Pain Manag. 2015, 5 (6), 455-464.

(36) Holey, L. A.; Dixon, J. Connective Tissue Manipulation: A Review of Theory and Clinical Evidence. J. Bodyw. Mov. Ther. 2014, $18(1), 112-118$.

(37) Turvey, M. T.; Fonseca, S. T. The Medium of Haptic Perception: A Tensegrity Hypothesis. J. Mot. Behav. 2014, 46 (3), 143-187.

(38) Zügel, M.; Maganaris, C. N.; Wilke, J.; Jurkat-Rott, K.; Klingler, W.; Wearing, S. C.; Findley, T.; Barbe, M. F.; Steinacker, J. M.; Vleeming, A.; Bloch, W.; Schleip, R.; Hodges, P. W. Fascial Tissue Research in Sports Medicine: From Molecules to Tissue Adaptation, Injury and Diagnostics: Consensus Statement. Br. J. Sports Med. 2018, 52 (23), 1497.

(39) Hodges, P. W.; Danneels, L. Changes in Structure and Function of the Back Muscles in Low Back Pain: Different Time Points, Observations, and Mechanisms. J. Orthop. Sports Phys. Ther. 2019, 49 (6), 464-476.

(40) Tesarz, J.; Hoheisel, U.; Wiedenhöfer, B.; Mense, S. Sensory Innervation of the Thoracolumbar Fascia in Rats and Humans. Neuroscience 2011, 194, 302-308.

(41) De Coninck, K.; Hambly, K.; Dickinson, J. W.; Passfield, L. Measuring the Morphological Characteristics of Thoracolumbar Fascia in Ultrasound Images: An Inter-Rater Reliability Study. BMC Musculoskelet. Disord. 2018, 19 (1), 1-6.

(42) Krause, F.; Wilke, J.; Vogt, L.; Banzer, W. Intermuscular Force Transmission along Myofascial Chains: A Systematic Review. J. Anat. 2016, 228 (6), 910-918.

(43) Langevin, H. M.; Fox, J. R.; Koptiuch, C.; Badger, G. J.; Greenan- Naumann, A. C.; Bouffard, N. A.; Konofagou, E. E.; Lee, W. N.; Triano, J. J.; Henry, S. M. Reduced Thoracolumbar Fascia Shear Strain in Human Chronic Low Back Pain. BMC Musculoskelet. Disord. 2011, 12.

(44) Langevin, H. M.; Stevens-Tuttle, D.; Fox, J. R.; Badger, G. J.; Bouffard, N. A.; Krag, M. H.; Wu, J.; Henry, S. M. Ultrasound Evidence of Altered Lumbar Connective Tissue Structure in Human Subjects with Chronic Low Back Pain. BMC Musculoskelet. Disord. 2009, 10 (1), 3479. 
(45) McGlone, F.; Wessberg, J.; Olausson, H. Discriminative and Affective Touch: Sensing and Feeling. Neuron 2014, 82 (4), 737-755.

(46) Wilke, J.; Krause, F.; Vogt, L.; Banzer, W. What Is Evidence-Based about Myofascial Chains: A Systematic Review. Arch. Phys. Med. Rehabil. 2016, 97 (3), 454-461.

(47) Wilke, J.; Niederer, D.; Vogt, L.; Banzer, W. Remote Effects of Lower Limb Stretching: Preliminary Evidence for Myofascial Connectivity? J. Sports Sci. 2016, 34 (22), 2145-2148.

(48) Chaudhry, H.; Schleip, R.; Ji, Z.; Bukiet, B.; Maney, M.; Findley, T. Three-Dimensional Mathematical Model for Deformation of Human Fasciae in Manual Therapy. J. Am. Osteopath. Assoc. 2008, 108 (8), 379-390.

(49) Cholewicki, J.; Breen, A.; Popovich, J. M.; Peter Reeves, N.; Sahrmann, S. A.; Van Dillen, L. R.; Vleeming, A.; Hodges, P. W. Can Biomechanics Research Lead to More Effective Treatment of Low Back Pain? A Point-Counterpoint Debate. J. Orthop. Sports Phys. Ther. 2019, 49 (6), 425-436.

(50) Puentedura, E. J.; Flynn, T. Combining Manual Therapy with Pain Neuroscience Education in the Treatment of Chronic Low Back Pain: A Narrative Review of the Literature. Physiother. Theory Pract. 2016, 32 (5), 408-414.

(51) Bialosky, J. E.; Bishop, M. D.; Penza, C. W. Placebo Mechanisms of Manual Therapy: A Sheep in Wolf's Clothing? J. Orthop. Sports Phys. Ther. 2017, 47 (5), 301-304.

(52) Wiech, K.; Ploner, M.; Tracey, I. Neurocognitive Aspects of Pain Perception. Trends Cogn. Sci. 2008, 12 (8), $306-313$.

(53) Mertens, P.; Blond, S.; David, R.; Rigoard, P. Anatomy, Physiology and Neurobiology of the Nociception: A Focus on Low Back Pain (Part A). Neurochirurgie 2015, 61 (S1), S22-S34.

(54) Wallwork, S. B.; Bellan, V.; Catley, M. J.; Moseley, G. L. Neural Representations and the Cortical Body Matrix: Implications for Sports Medicine and Future Directions. Br. J. Sports Med. 2016, 50 (16), 990-996.

(55) Bittencourt, N. F. N.; Meeuwisse, W. H.; Mendonça, L. D.; Nettel-Aguirre, A.; Ocarino, J. M.; Fonseca, S. T. Complex Systems Approach for Sports Injuries: Moving from Risk Factor Identification to Injury Pattern Recognition - Narrative Review and New Concept. Br. J. Sports Med. 2016, 50 (21), 1309-1314.

(56) Huysmans, E.; Ickmans, K.; Van Dyck, D.; Nijs, J.; Gidron, Y.; Roussel, N.; Polli, A.; Moens, M.; Goudman, L.; De Kooning, M. Association Between Symptoms of Central Sensitization and Cognitive Behavioral Factors in People With Chronic Nonspecific Low Back Pain: A Cross-Sectional Study. J. Manipulative Physiol. Ther. 2018, 41 (2), 92-101.

(57) Louw, A.; Puentedura, E. J.; Diener, I.; Zimney, K. J.; Cox, T. Pain Neuroscience Education: Which Pain Neuroscience Education Metaphor Worked Best? South African J. Physiother. 2019, 75 (1), 1-7.

(58) Wood, L.; Hendrick, P. A. A Systematic Review and Meta-Analysis of Pain Neuroscience Education for Chronic Low Back Pain: Short-and Long-Term Outcomes of Pain and Disability. Eur. J. Pain (United Kingdom) 2019, 23 (2), $234-249$. 